\title{
RELATIONSHIP BETWEEN CONCENTRATION AND TEMPORAL DURATION ESTIMATION: IMPLICATIONS FOR FLOW EXPERIENCE
}

\author{
Jun SAIKI, and Eiko INOUE \\ Kyoto University, Kyoto, Japan
}

\begin{abstract}
It has been suggested that high concentration or flow experience alters the sensation of time. Additionally, attention is known to affect the perception of time. To investigate whether the effect of concentration on time perception is equivalent to that of attention, we investigated the correlation between subjective concentration and the judgment of temporal duration through 3 experiments employing 8 everyday tasks. The results showed that concentration rating was not significantly correlated with duration estimates in ordinary time units and was negatively correlated with categorical duration judgment. With the feedback of physical elapsed time, categorical duration judgment eliminated the correlation, suggesting that concentration was correlated with duration judgment only when the participants did not have access to information concerning duration. Unlike attention, concentration had an effect on subjective time impression but not on duration estimation, suggesting that it affects time perception differently from effort-based mechanisms.
\end{abstract}

Key words: concentration, time perception, flow experience, attention, effort

Various factors, both external and internal, constitute happiness. External factors such as food, money, and other external rewards have been investigated by experimental psychology by quantitatively manipulating rewards. However, internal factors for happiness are much more difficult to define and manipulate, and thus, few experiments have been conducted in this area. It is obvious that one often feels happy even in the absence of external reward. For example, playing musical instruments and participating in sports and games does not typically provide rewards (except for professional players); nonetheless, one does experience happiness. To capture such internal aspects, Deci and colleagues conducted empirical studies under the notion of intrinsic motivation (Deci \& Ryan, 1985). However, despite their efforts, it remains largely unknown how these intrinsic factors lead to happiness.

Csikszentmihalyi and his colleagues (Csikszentmihalyi, 1990; Csikszentmihalyi \& Nakamura, 2010) introduced the notion of flow to capture more intrinsic aspects of happiness in human activity. A flow experience is defined as "the state of effortless concentration so deep that they lose their sense of time, of themselves, of their problem

This work was supported by a Grant-in-Aid for Global COE (Centers of Excellence) Program (D07) by Japan's Ministry of Education, Culture, Sports, Science, and Technology. Correspondence and requests for materials should be addressed to Jun Saiki (e-mail: saiki@cv.jinkan.kyoto-u.ac.jp).

Correspondence concerning this article should be addressed to Jun Saiki, Graduate School of Human and Environmental Studies, Kyoto University, Yoshida-Nihonmatsucho, Sakyo, Kyoto 606-8501, Japan (e-mail: saiki@cv.jinkan.kyoto-u.ac.jp). 
when people enjoy most what they are doing" (Csikszentmihalyi \& Nakamura, 2010, pp. 181). The notion of flow fits nicely with everyday activities in a subjective sense. Csikszentmihalyi and Larson devised the Experience Sampling Method (ESM) to investigate the quality of subjective experience in a more systematic fashion (Csikszentmihalyi \& Larson, 1987) and revealed many important characteristics of flow experiences.

One important characteristic of flow experience is its effortlessness despite efficient task performance, which is markedly different from the level of effort required by attentive processing, as discussed in experimental psychology (Kahneman, 1973). In the literature on attention, the effort expended in attentional processing is assumed to be proportional to task performance; thus, it is difficult to explain flow experience and efficient task performance without effort in the context of the standard framework of attention. The flow experience may be quite a special mental state, or may indicate a more general nonlinear relationship between attention and effort. Because of the lack of experimental investigations of flow experiences, the fundamental issue of the underlying mechanisms of "effortless attention" remains unknown.

Another peculiar characteristic of flow experience is its altered sense of time. Subjective reports say that estimated temporal duration becomes shorter when one is in the state of flow, which is consistent with the everyday impression that time flies when one is in a highly concentrated state. However, this aspect of flow experience is rather consistent with the effect of attention. Studies on attention and temporal duration estimation have shown that when participants are aware that a duration judgment must be made, they tend to increasingly underestimate the time taken as the engagement of attention increases (Block \& Zakay, 1996; Chaston \& Kingstone, 2008; Zakay \& Block, 2004). Therefore, it appears that temporal duration estimation may reflect some common characteristics of attention and concentration.

However, the standard explanation of attentional effect on duration estimation casts some doubts on this simple relationship. This explanation utilizes the notion that an increase in effort on an activity results in an underestimation of time spent on it. When one attends to the main task, more processing resources, presumably proportional to the amount of effort, are allocated to it, resulting in fewer resources available for duration estimation (Block \& Zakay, 1997). This account is obviously inconsistent with the effects of concentration, which is characterized as effortless. Thus, attention and concentration may affect duration estimation in the same direction, with different underlying mechanisms.

In the current study, we defined effort, attention, and concentration in the following way. Effort is the amount of psychological resource deployed to an activity. Attention is a mechanism of allocating resource to execute tasks efficiently, with the assumption that the level of attention is proportional to the amount of effort. In contrast, concentration is a mechanism of selective information processing with a nonlinear relation with effort. A high concentration may lead to efficient performance with low effort. Note that concentration is not equivalent to flow experience. The flow is an extreme state of concentration. 
To investigate the nature of concentration, the current study conducted a series of experiments examining the correlation between subjective concentration and temporal duration estimates. Past studies on concentration or flow experiences rely on subjective reports or reports from studies using ESM, and few systematic experiments have been conducted (Keller \& Bless, 2008; Moller, Meier, \& Wall, 2010). Previous experimental studies utilized video games such as Tetris and Pac-Man, and by manipulating the balance of skill and challenge, they succeeded in inducing flow experiences. However, they failed to observe altered time sensation with flow experience.

To investigate the relationship between duration estimation and concentration or flow, our study took an alternative approach. It employed a series of naturalistic cognitive tasks instead of well-controlled cognitive experimental tasks, such as attention research (Zakay \& Block, 2004), or a single game with various conditions, as in flow research (Keller \& Bless, 2008). To induce a flow experience, or at least various degrees of concentration, we selected tasks lasting three to five minutes, which appear to be necessary to induce concentrated states.

To understand the similarity and differences between attention and concentration, we employed different kinds of duration estimation methods that appeared in the literature of attention and time perception. These methods (detailed below) have shown a consistent pattern of results in attention studies. Thus, if the effects of concentration are simply the effects of attention, one expects a negative correlation between concentration and temporal duration estimation such that estimated duration becomes shorter when one is in a more concentrated state, regardless of the methods of estimation. In fact, the experiments showed that the correlation between concentration and duration estimates depends on the method of estimation. This suggests that concentration differs from attention in terms of its effects on duration estimation.

\section{General Method}

\section{Materials}

The experiments consisted of eight tasks selected on the basis of their typical execution time. They usually require several minutes, the minimum amount of time necessary to experience subjective concentration. They were (1) solving a $6 \times 6$ puzzle, (2) oral reading, (3) playing a Reversi game, (4) completing a transcription, (5) undertaking a cognitive task, (6) performing the 100 squares calculation, (7) copying a line drawing, and (8) building using LEGO bricks. Each task is described below in further detail.

Task 1 . Solving a $6 \times 6$ puzzle: A $6 \times 6$ matrix was composed of six submatrices of $2 \times 3$ cells (Fig. 1a). Several cells were filled with a number between 1 and 6 as cues. The participants' task was to fill numbers in the remaining cells and make all rows, columns, and submatrices contain numbers 1 to 6 without repetition. The $6 \times 6$ matrix resembled a SUDOKU puzzle.

Task 2. Oral reading: Participants read aloud a passage of Japanese text three pages long from the book "Children's brain is located on their skin" (literal translation) by So Yamaguchi (2004).

Task 3. Playing a Reversi game: This is a board game previously marketed under the trade name Othello (Fig. 1b). In order to ensure that all participants were equally matched, we used a computerized online version of the Reversi game. The competition level was set to "medium." Given an $8 \times 8$ matrix, a participant and the computer would take turns to place a piece. The players had to have as many of their colored pieces showing by turning over their opponent's pieces. The game continued until one them lost of their pieces or until all the cells were filled. 
a.

\begin{tabular}{|l|l|l|l|l|l|}
\hline & 1 & & & 3 & \\
\hline 3 & 4 & 6 & 2 & 5 & 1 \\
\hline & 6 & 2 & 3 & 4 & \\
\hline & 5 & 3 & 1 & 6 & \\
\hline 5 & 3 & 1 & 6 & 2 & 4 \\
\hline & 2 & & & 1 & \\
\hline
\end{tabular}

C.

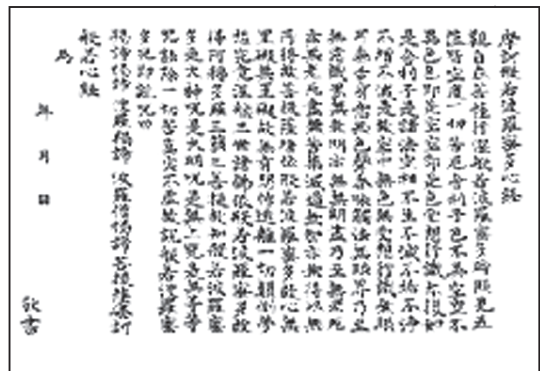

e.

\begin{tabular}{|c|c|c|c|c|c|c|c|c|c|c|}
\hline+ & 8 & 2 & 6 & 4 & 1 & 7 & 3 & 5 & 0 & 9 \\
\hline 8 & & & & & & & & & & \\
\hline 2 & & & & & & & & & & \\
\hline 6 & & & & & & & & & & \\
\hline 4 & & & & & & & & & & \\
\hline 1 & & & & & & & & & & \\
\hline 7 & & & & & & & & & & \\
\hline 3 & & & & & & & & & & \\
\hline 5 & & & & & & & & & & \\
\hline 0 & & & & & & & & & & \\
\hline 5 & & & & & & & & & & \\
\hline
\end{tabular}

g.

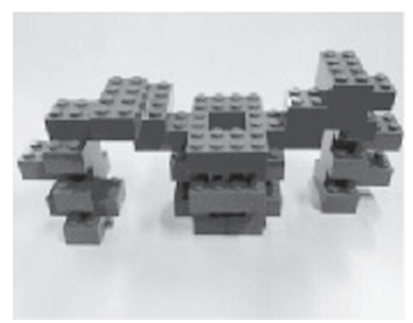

b.

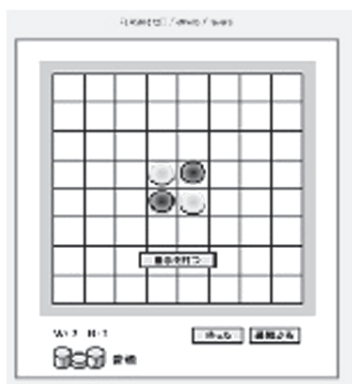

d.

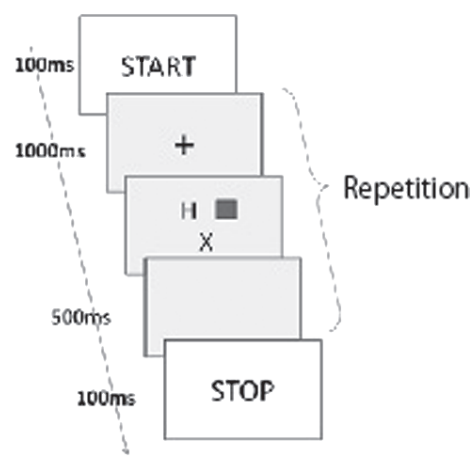

f.

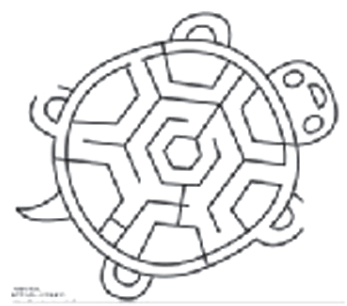

Fig. 1. Materials used in Experiments 1-3. (a) $6 \times 6$ puzzle, (b) the Reversi game, (c) the Wisdom sutra for transcription, (d) a block structure and time course of a single trial of a cognitive task, (e) the form for 100 squares calculation, (f) line drawing used for copying, and (g) 3-D object for the LEGO bricks task. 
Task 4. Completing a transcription: Participants were to copy the first 34 characters of a sutra (a Buddist scripture) called "hannya-shingyo" (the Wisdom Sutras) in Chinese characters (Fig. 1c). They received a sheet with the sutra printed in gray and traced the characters with a calligraphy pen.

Task 5. Undertaking a cognitive task: A selective attention task used by Lavie (1995) was employed with some modifications. The stimulus display consisted of a target letter, a distractor letter, and a geometric figure irrelevant to the task. The letters and the geometric figures subtended $0.36^{\circ} \times 0.25^{\circ}$ and $0.36^{\circ} \times 0.36^{\circ}$ of visual angle, respectively. The target letters were $\mathrm{H}$ and $\mathrm{U}$, and the distractors were $\mathrm{H}, \mathrm{U}$, and $\mathrm{X}$. The geometric figures used were a red circle, red square, blue circle, and blue square. The target and geometric figures were presented horizontally at the center flanking the fixation point location. They were separated by $0.7^{\circ}$, and the target location was randomized between the right and left of the central point. The distractor letter was presented either $1.3^{\circ}$ above or below the fixation location.

The task was to judge the identity of the target and press one key when it was $\mathrm{H}$ and another key when it was $\mathrm{U}$ as quickly and accurately as possible. The distractor letter was either compatible with the target, incompatible with the target (i.e., a letter assigned the opposite response), or neutral (i.e., $\mathrm{X}$ with no response assigned). The geometric figure was irrelevant to the task.

The task was composed of 12 blocks of 4-8 trials. Each block began with the display "START" for $100 \mathrm{~ms}$, followed by a series of trials (Fig. 1d). Each trial began with the fixation cross for $1000 \mathrm{~ms}$, followed by the stimulus display until a response was received. A $500 \mathrm{~ms}$ blank display followed the response. At the end of a block, the display "STOP" was presented for $100 \mathrm{~ms}$. The next block began after the participant pressed a key four times. The experimental program was written using MATLAB with a psychophysics toolbox extension (Brainard, 1997; Pelli, 1997).

Task 6. Performing the 100 squares calculation: Participants were required to perform a series of 100 additions of single digit numbers in a systematic fashion. The calculation form was composed of a $10 \times 10$ matrix, with an additional row on top and an additional column at the left filled with a single digit number from 0 to 9 in random order (Fig. 1e). Participants filled the calculated value of two numbers in the corresponding row and column row by row, starting from the top-left cell and ending with the bottom-right cell. To adjust the task completion time within several minutes, participants performed these calculations twice.

Task 7. Copying a line drawing: The participants received a sheet of A4 size paper with a complex line drawing of a maze with a turtle shape in its top half. They were instructed to copy the line drawing in the bottom half (Fig. 1f).

Task 8. Building using LEGO bricks: Participants were given a complex 3D shape built from 28 identically shaped blue LEGO bricks and asked to construct the same object with the same LEGO bricks (Fig. 1g). They were allowed to touch the model during construction.

For a psychological measurement of subjective concentration, a 10-point scale was used, with 1 being the least concentrated and 10 being the most concentrated states. We used the Japanese term "shuchu" for concentration, and did not provide any further definition or clarifications about the term. Thus, participants made judgment based on their subjective understanding of the term. For temporal duration judgment, each experiment used different methods, as described in the section for individual experiments.

Procedure

For each task, participants first received the instruction and then began the task on the experimenter's signal. They were instructed to concentrate on the task and signal its completion by raising their hand. The experimenter measured the elapsed time with a stopwatch. After the completion of each task, they were asked to rate their subjective concentration and make a duration judgment. The order of the 8 tasks was counterbalanced across participants. 


\section{EXPERIMENT 1}

Experiment 1 used a direct estimation of elapsed time in ordinary time units (minutes and seconds).

\section{Participants}

Fifty undergraduate and graduate students at Kyoto University participated in the experiment with informed (written) consent. All of them had normal or corrected to normal vision and were naive to the experimental hypothesis.

\section{Materials}

Temporal duration judgment was conducted by verbal estimation in minutes and seconds. They reported their estimation of elapsed time in 10-second units, for example, 3 minutes and 40 seconds.

\section{RESULTS AND DISCUSSION}

Table 1 shows the mean physical elapsed time, mean estimated time, mean of concentration judgment, correlation between physical time and concentration judgment, and correlation between estimated time and concentration judgment. The mean and standard deviation (SD) of physical elapsed time varied across tasks. For example, the $6 \times 6$ puzzle, transcription, and copying of the line diagram experiments showed a longer mean elapsed time than those of other experiments. The $6 \times 6$ puzzle and transcription exhibited a larger SD as well. In contrast, the cognitive task, oral reading, and 100 squares calculation experiments showed smaller SDs than those of other experiments. Thus, the variability in the mean and SD may reflect characteristics of each task.

The mean rate of subjective concentration ranged between 6.1 and 7.8, but SDs were comparable.

Traditionally, the evaluation of the correlation between concentration and time perception is accomplished by considering a direct correlation between concentration rating and estimated time. However, for the purposes of this study, we used the following measures. For the concentration rating, we normalized the rating score for each participant because the range of rating scales used by participants differed substantially. For the estimated time, we defined the deviation index as the difference between the estimated time and physical time divided by the physical time. Thus, the deviation index takes a positive value when the estimated time exceeds the actual elapsed time and a negative value when it is less than the actual elapsed time.

The correlation between normalized concentration rating and the deviation index of duration judgment was found to be statistically significant only for the Reversi game task and displayed a positive correlation. This suggested that the more concentrated the state, the greater the overestimate of duration. Other tasks failed to show a significant correlation. Overall, when elapsed time was judged directly using minutes and seconds as the indicator, there was no evidence to suggest that time flies when one is concentrating on a task. 
Table 1. Mean Physical Elapsed Time, Mean Estimated Time, Mean of Concentration Judgment, Correlation Between Physical Time and Concentration Judgment, and Correlation Between Estimated Time and Concentration Judgment in Experiment 1.

\begin{tabular}{|c|c|c|c|c|c|}
\hline Task & $\begin{array}{l}\text { Elapsed } \\
\text { time } \\
\text { (s) }\end{array}$ & $\begin{array}{l}\text { Time } \\
\text { judgment } \\
\text { (s) }\end{array}$ & Concentration & $\begin{array}{l}\text { Correlation between } \\
\text { time judgment and } \\
\text { concentration }\end{array}$ & $\begin{array}{l}\text { Correlation between } \\
\text { elapsed time and } \\
\text { concentration }\end{array}$ \\
\hline $\begin{array}{l}\text { Solving a } 6 \times 6 \\
\text { puzzle }\end{array}$ & $\begin{array}{c}389.26 \\
(246.34)\end{array}$ & $\begin{array}{c}343.40 \\
(196.36)\end{array}$ & $\begin{array}{c}7.40 \\
(1.76)\end{array}$ & -0.06 & -0.15 \\
\hline Oral reading & $\begin{array}{l}200.62 \\
(44.19)\end{array}$ & $\begin{array}{l}195.60 \\
(68.87)\end{array}$ & $\begin{array}{c}7.12 \\
(1.67)\end{array}$ & 0.08 & -0.09 \\
\hline $\begin{array}{l}\text { Playing a Reversi } \\
\text { game }\end{array}$ & $\begin{array}{c}170.42 \\
(105.64)\end{array}$ & $\begin{array}{c}191.60 \\
(107.31)\end{array}$ & $\begin{array}{c}6.06 \\
(1.89)\end{array}$ & $0.32 *$ & 0.01 \\
\hline Transcription & $\begin{array}{c}275.74 \\
(149.38)\end{array}$ & $\begin{array}{c}269.80 \\
(144.37)\end{array}$ & $\begin{array}{c}6.72 \\
(1.93)\end{array}$ & $-0.25+$ & $0.27+$ \\
\hline $\begin{array}{l}\text { Undertaking a } \\
\text { cognitive task }\end{array}$ & $\begin{array}{l}221.72 \\
(24.59)\end{array}$ & $\begin{array}{l}241.60 \\
(70.29)\end{array}$ & $\begin{array}{c}7.82 \\
(1.41)\end{array}$ & -0.03 & -0.22 \\
\hline $\begin{array}{l}100 \text { squares } \\
\text { calculation }\end{array}$ & $\begin{array}{l}193.54 \\
(37.82)\end{array}$ & $\begin{array}{l}196.60 \\
(80.19)\end{array}$ & $\begin{array}{c}7.64 \\
(1.47)\end{array}$ & -0.22 & -0.02 \\
\hline $\begin{array}{l}\text { Copying a line } \\
\text { drawing }\end{array}$ & $\begin{array}{c}304.94 \\
(122.58)\end{array}$ & $\begin{array}{l}273.60 \\
(89.25)\end{array}$ & $\begin{array}{c}7.24 \\
(1.49)\end{array}$ & 0.04 & 0.22 \\
\hline $\begin{array}{l}\text { Building using } \\
\text { LEGO bricks }\end{array}$ & $\begin{array}{l}227.16 \\
(99.46)\end{array}$ & $\begin{array}{l}209.40 \\
(89.63)\end{array}$ & $\begin{array}{c}7.52 \\
(1.37)\end{array}$ & -0.12 & 0.08 \\
\hline
\end{tabular}

Standard Deviations are in Parentheses. Symbols * and + Denote Statistically Significant Result at $\alpha=.05$, and Marginally Significant Result $(.05<p<.10)$, Respectively.

\section{EXPERIMENT 2}

Experiment 2 used a categorical estimation of elapsed time with a 9-point rating scale.

\section{Participants}

Fifty undergraduate and graduate students at Kyoto University participated in the experiment with informed (written) consent. None of them participated in Experiment 1. All of them had normal or corrected to normal vision and were naive to the experimental hypothesis.

\section{Materials}

Temporal duration judgment was conducted using a categorical rating scale with 9 points, where " 4 " means long and " -4 " means short. Participants were instructed to rate subjective temporal duration without any feedback about physical duration. The central point of the scale (“ 0 ") means that subjective temporal duration is neither long nor short. 
Table 2. Mean Physical Elapsed Time, Mean Estimated Time, Mean of Concentration Judgment, Correlation Between Physical Time and Concentration Judgment, and Correlation Between Estimated Time and Concentration Judgment in Experiment 2.

\begin{tabular}{|c|c|c|c|c|c|}
\hline Task & $\begin{array}{l}\text { Elapsed } \\
\text { time } \\
\text { (s) }\end{array}$ & $\begin{array}{c}\text { Time } \\
\text { judgment }\end{array}$ & Concentration & $\begin{array}{l}\text { Correlation between } \\
\text { time judgment and } \\
\text { concentration }\end{array}$ & $\begin{array}{c}\text { Correlation between } \\
\text { elapsed time and } \\
\text { concentration }\end{array}$ \\
\hline $\begin{array}{l}\text { Solving a } 6 \times 6 \\
\text { puzzle }\end{array}$ & $\begin{array}{c}414.62 \\
(183.27)\end{array}$ & $\begin{array}{c}0.44 \\
(2.07)\end{array}$ & $\begin{array}{l}7.38 \\
(2.05)\end{array}$ & 0.05 & 0 \\
\hline Oral reading & $\begin{array}{l}179.68 \\
(30.94)\end{array}$ & $\begin{array}{l}-0.50 \\
(1.59)\end{array}$ & $\begin{array}{c}7.30 \\
(1.75)\end{array}$ & -0.08 & -0.1 \\
\hline $\begin{array}{l}\text { Playing a Reversi } \\
\text { game }\end{array}$ & $\begin{array}{c}168.92 \\
(101.29)\end{array}$ & $\begin{array}{l}-0.28 \\
(1.62)\end{array}$ & $\begin{array}{l}6.56 \\
(2.01)\end{array}$ & -0.13 & 0.13 \\
\hline Transcription & $\begin{array}{c}229.02 \\
(112.92)\end{array}$ & $\begin{array}{l}-0.20 \\
(1.51)\end{array}$ & $\begin{array}{c}7.28 \\
(1.58)\end{array}$ & $-0.47 * *$ & 0.07 \\
\hline $\begin{array}{l}\text { Undertaking a } \\
\text { cognitive task }\end{array}$ & $\begin{array}{l}229.22 \\
(33.06)\end{array}$ & $\begin{array}{l}-0.16 \\
(1.52)\end{array}$ & $\begin{array}{c}7.14 \\
(1.81)\end{array}$ & $-0.31^{*}$ & $-0.26+$ \\
\hline $\begin{array}{l}100 \text { squares } \\
\text { calculation }\end{array}$ & $\begin{array}{l}204.32 \\
(40.22)\end{array}$ & $\begin{array}{l}-0.14 \\
(1.53)\end{array}$ & $\begin{array}{c}7.68 \\
(1.74)\end{array}$ & $-0.33^{*}$ & -0.22 \\
\hline $\begin{array}{l}\text { Copying a line } \\
\text { drawing }\end{array}$ & $\begin{array}{l}257.12 \\
(88.80)\end{array}$ & $\begin{array}{c}-0.44 \\
(1.39)\end{array}$ & $\begin{array}{c}7.36 \\
(1.55)\end{array}$ & $-0.34 *$ & -0.06 \\
\hline $\begin{array}{l}\text { Building using } \\
\text { LEGO bricks }\end{array}$ & $\begin{array}{l}195.30 \\
(69.41)\end{array}$ & $\begin{array}{l}-0.32 \\
(1.65)\end{array}$ & $\begin{array}{l}8.08 \\
(1.34)\end{array}$ & $-0.46^{*}$ & 0.07 \\
\hline
\end{tabular}

Standard Deviations are in Parentheses. Symbols **, * and + Denote Statistically Significant Result at $\alpha=.01$, at $\alpha=.05$, and Marginally Significant Result $(.05<p<.10)$, Respectively.

\section{RESULTS AND DISCUSSION}

Table 2 shows the mean physical elapsed time, mean estimated time, mean of concentration rating, correlation between physical time and concentration rating, and correlation between estimated time and concentration rating. The physical elapsed time and concentration rating displayed a pattern similar to that seen in Experiment 1, suggesting that a change in duration judgment affected neither task performance nor concentration rating.

However, the correlation between normalized concentration rating and duration judgment revealed a marked difference from that seen in Experiment 1. As shown in Table 2, transcription, cognitive task, 100 squares calculation, copying a line drawing, and building LEGO bricks displayed a significant negative correlation, suggesting that estimated duration becomes shorter when one is concentrating on a task.

According to the flow literature, the lack of correlation observed in the experiment for the oral reading and Reversi game tasks may be accounted for in the following way. The induction of flow experiences usually requires a good balance of challenge and skill; thus, compared to an individual's skill level, the assigned task should neither be too difficult nor too easy. For example, oral reading is a familiar skill for participants in this 
study; thus, this task may be too easy for them. However, the medium level of competition in the computerized Reversi game was in fact too tough for most participants, which likely resulted in their losing concentration during the game. The lack of correlation observed with the $6 \times 6$ puzzle task may be attributed to large individual differences, given that the physical elapsed time ranged from 1 minute to more than 10 minutes.

Experiments 1 and 2 revealed differing patterns of correlation between concentration and duration estimation, suggesting that the way subjective time is estimated significantly affects the obtained results. There are two alternative interpretations for this discrepancy. First, different types of response may have different sensitivity to subjective time sensation. Compared to the duration estimate in ordinal time units, the categorical rating of the elapsed time may be more sensitive to subjective time sensation. We term this alternative as "response mode hypothesis." Second, it is possible that the temporal information used in the judgment, and not the response mode, may be the critical factor. While a duration estimate requires access to the temporal duration for task completion, the categorical rating may be based on the subjective speed of the internal clock, which in turn may not involve monitoring the clock for the entire task period. We term this alternative as "temporal information hypothesis." Experiment 3 was devised to test these two alternatives.

\section{EXPERIMENT 3}

Experiment 3 used a categorical estimation of elapsed time (as in Experiment 2), supplemented with feedback of physical elapsed time. The response mode hypothesis predicts a negative correlation as in Experiment 2. The temporal information hypothesis predicts a lack of correlation, as in Experiment 1, because given the knowledge of physical elapsed time, participants are likely to rely on temporal duration while making their judgment.

\section{Participants}

Fifty undergraduate and graduate students at Kyoto University participated in the experiment with informed (written) consent. None of them participated in either Experiment 1 or 2 . All of them had normal or corrected to normal vision and were naive to the experimental hypothesis.

\section{Procedure}

The procedure employed was identical to that used in Experiment 2, except that for each task, the physical elapsed time was provided by the experimenter before asking the participants for their estimate of duration. Therefore, participants were asked to judge their subjective duration using physical duration as the standard. 
Table 3. Mean Physical Elapsed Time, Mean Estimated Time, Mean of Concentration Judgment, Correlation Between Physical Time and Concentration Judgment, and Correlation Between Estimated Time and Concentration Judgment in Experiment 3.

\begin{tabular}{|c|c|c|c|c|c|}
\hline Task & $\begin{array}{l}\text { Elapsed } \\
\text { time } \\
\text { (s) }\end{array}$ & $\begin{array}{c}\text { Time } \\
\text { judgment }\end{array}$ & Concentration & $\begin{array}{l}\text { Correlation between } \\
\text { time judgment and } \\
\text { concentration }\end{array}$ & $\begin{array}{l}\text { Correlation between } \\
\text { elapsed time and } \\
\text { concentration }\end{array}$ \\
\hline $\begin{array}{l}\text { Solving a } 6 \times 6 \\
\text { puzzle }\end{array}$ & $\begin{array}{c}361.28 \\
(224.93)\end{array}$ & $\begin{array}{c}0.12 \\
(2.09)\end{array}$ & $\begin{array}{c}7.70 \\
(1.78)\end{array}$ & -0.2 & -0.14 \\
\hline Oral reading & $\begin{array}{l}186.44 \\
(24.75)\end{array}$ & $\begin{array}{c}0.30 \\
(1.63)\end{array}$ & $\begin{array}{c}6.70 \\
(1.52)\end{array}$ & -0.02 & -0.14 \\
\hline $\begin{array}{l}\text { Playing a Reversi } \\
\text { game }\end{array}$ & $\begin{array}{l}168.48 \\
(86.15)\end{array}$ & $\begin{array}{l}-1.12 \\
(1.52)\end{array}$ & $\begin{array}{c}6.44 \\
(1.80)\end{array}$ & -0.23 & -0.05 \\
\hline Transcription & $\begin{array}{c}258.50 \\
(108.77)\end{array}$ & $\begin{array}{c}0.70 \\
(1.76)\end{array}$ & $\begin{array}{c}6.84 \\
(1.31)\end{array}$ & -0.16 & -0.13 \\
\hline $\begin{array}{l}\text { Undertaking a } \\
\text { cognitive task }\end{array}$ & $\begin{array}{l}225.28 \\
(16.79)\end{array}$ & $\begin{array}{l}-0.12 \\
(1.81)\end{array}$ & $\begin{array}{c}7.06 \\
(1.96)\end{array}$ & -0.1 & $0.27+$ \\
\hline $\begin{array}{l}100 \text { squares } \\
\text { calculation }\end{array}$ & $\begin{array}{l}206.82 \\
(45.03)\end{array}$ & $\begin{array}{c}-0.42 \\
(1.90)\end{array}$ & $\begin{array}{l}8.08 \\
(1.64)\end{array}$ & -0.09 & -0.24 \\
\hline $\begin{array}{l}\text { Copying a line } \\
\text { drawing }\end{array}$ & $\begin{array}{c}304.12 \\
(160.90)\end{array}$ & $\begin{array}{c}0.26 \\
(1.79)\end{array}$ & $\begin{array}{c}7.18 \\
(1.49)\end{array}$ & -0.22 & 0.03 \\
\hline $\begin{array}{l}\text { Building using } \\
\text { LEGO bricks }\end{array}$ & $\begin{array}{l}199.62 \\
(77.16)\end{array}$ & $\begin{array}{l}-0.80 \\
(1.58)\end{array}$ & $\begin{array}{c}7.64 \\
(1.50)\end{array}$ & -0.18 & 0.14 \\
\hline
\end{tabular}

Standard Deviations are in Parentheses. Symbol + Denotes Marginally Significant Result $(.05<p<.10)$.

\section{RESULTS AND DISCUSSION}

Table 3 shows the mean physical elapsed time, mean estimated time, mean of concentration rating, correlation between physical time and concentration rating, and correlation between estimated time and concentration rating. The physical elapsed time and concentration rating showed a pattern similar to that seen in Experiments 1 and 2, suggesting that the change in duration judgment affected neither task performance nor concentration rating.

Importantly, the negative correlation between normalized concentration rating and duration judgment in Experiment 2 disappeared in Experiment 3. None of the eight tasks showed any significant correlation, supporting the temporal information hypothesis. Therefore, the negative correlation observed in Experiment 2 may be attributed to the use of subjective speed of the internal clock for temporal judgment.

\section{GeNeral DisCuSSION}

The current study investigated the relationship between subjective concentration and temporal duration estimation in everyday tasks, such as performing calculations, reading, and solving puzzles. The experiments were conducted to test the subjective impression 
that time flies when one is in a more concentrated state. A series of three experiments revealed that correlation between concentration and duration estimation depends on how duration is estimated. When participants were asked to judge the duration of task execution directly, or judge relative time compared to physical elapsed time, no significant correlation was observed. However, when they were asked to judge subjective duration with a categorical scale, most of the tasks showed a significant negative correlation consistent with subjective impression.

The current findings suggest that the effect of concentration is unlikely to produce a general reduction in the speed of one's internal clock; if this were so, we would have observed a negative correlation between concentration and duration estimate, regardless of the method of estimation. Moreover, the lack of correlation with the direct estimation of task duration suggests that the effects of concentration are not equivalent to those of attention. The literature of attention and time perception has consistently shown that attention to a task reduces the estimated duration of its execution, which is accounted for by the reduction in the amount of processing resource for duration estimation. Since the current study failed to show the effect of concentration on duration estimation, it strongly suggests that concentration affects duration estimation differently from attention. Assuming that the notion of concentration captures some aspects of flow, although phenomenological descriptions of the effects of flow and attention on duration estimation are similar (in the sense that both make time fly), their underlying mechanisms may be fundamentally different. In the following, we propose a hypothetical account of the effect of attention and flow (or concentration) on time perception.

\section{Hypothetical Account of the Effect of Attention and Concentration on Time Perception}

First of all, we assume that there is a functional internal clock used for time perception at a cognitive level. Although there are considerable arguments regarding the neural implementation of such a clock, such as distributed versus centralized clocks (Ivry \& Schlerf, 2008), and clocks used at different time scales (Lewis \& Miall, 2009), a single functional clock at the scale of minutes is sufficient for the current account.

Temporal duration judgments are performed in various ways with this cognitive clock, and here, it is possible to make a distinction between two kinds of judgments: duration judgment and subjective judgment of clock speed. Duration judgment inherently requires counting the ticks of the clock, whereas clock speed judgment does not necessarily use duration information. Clock speed judgment can be made by sampling clock information for a short period of time instead of counting the ticks throughout the task. Presumably, duration judgment is necessary for time judgment in Experiment 1, whereas clock speed judgment is sufficient for categorical judgment in Experiment 2. The categorical judgment supplemented with feedback on physical duration in Experiment 3, probably encouraged the use of duration judgments.

We also present some assumptions regarding the relationship between concentration and attention. The notion of concentration has some characteristics similar to the notion of flow, such that one is fully attending, but not effortful. The notion of attention in the literature on attention and time judgment is almost identical to the notion of effort, such 
that directed attention to a task allocates more effort to the task. Overall, the effects of attention discussed in the literature are in fact the effects of effort, and the effect of concentration is somewhat special, because the monotonic relationship between attention and effort is violated. Following the phenomenological description of flow experience, we consider the concentrated state as fully attentive, thus being able to undertake efficient information processing even while it may be effortless. We also reserve the term "attention" to deal with a monotonic relationship between effort and processing efficiency.

Under these assumptions, the results of the current study can be explained in the following way. The more concentrated on the task, the slower the cognitive clock will be, thus leading to the significant negative correlation between concentration ratings and categorical time judgment, reflecting clock speed judgment. However, this account raises the question why duration judgment does not show similar biases. This result can be accounted for by assuming that the counting process of duration judgment can take account of the change in clock speed. Thus, while participants feel that clock is slowed down when they are concentrating on a task, they estimate the duration by correcting for the clock speed change in the counting process.

The effect of attention on duration judgment can be explained by the account in previous studies. When attention is directed to the task, less effort is allocated to the mechanism of duration judgment. This reduction of effort affects the precision of duration estimation. The lower precision of duration estimation occurs either by imprecise counting of clock ticks, or by imprecise clock speed correction in the counting process, both leading to an underestimate of duration.

Critically, in the concentrated state, the mind is effortlessly held in a fully attentive state, and thus, the precision of the counting process is not affected. Therefore, with time estimation using duration judgment, concentration does not affect duration judgment. Fig. 2 illustrates the relationship among concentration, attention, componential processes for time perception, and behavioral measures for time judgment to account for the observed correlations.

One important question that remains to be answered is the reason for the slowing of the cognitive clock. There are at least two possibilities. First, attention, regardless of effortful attention usually discussed in the literature, or effortless attention (such as flow or concentration), makes the clock slower. In this case, effortful attention affects both clock speed and precision of duration estimation, the latter being in fact the effect of effort. The concentration or flow affects only clock speed and not the precision of duration estimation. Alternatively, the speed of the cognitive clock may change only in special cases relating to flow or concentration. This account is also consistent with the current findings, because the effect of attention can be explained by imprecise counting of clock ticks without clock speed change.

The critical test of which alternative is more plausible lies in the effect of effortful attention on categorical time judgment without duration estimation. If attention in general slows the clock speed, effortful attention makes categorical time judgment shorter. However, if the clock speed changes only in special cases, effortful attention does not affect categorical time judgment. 


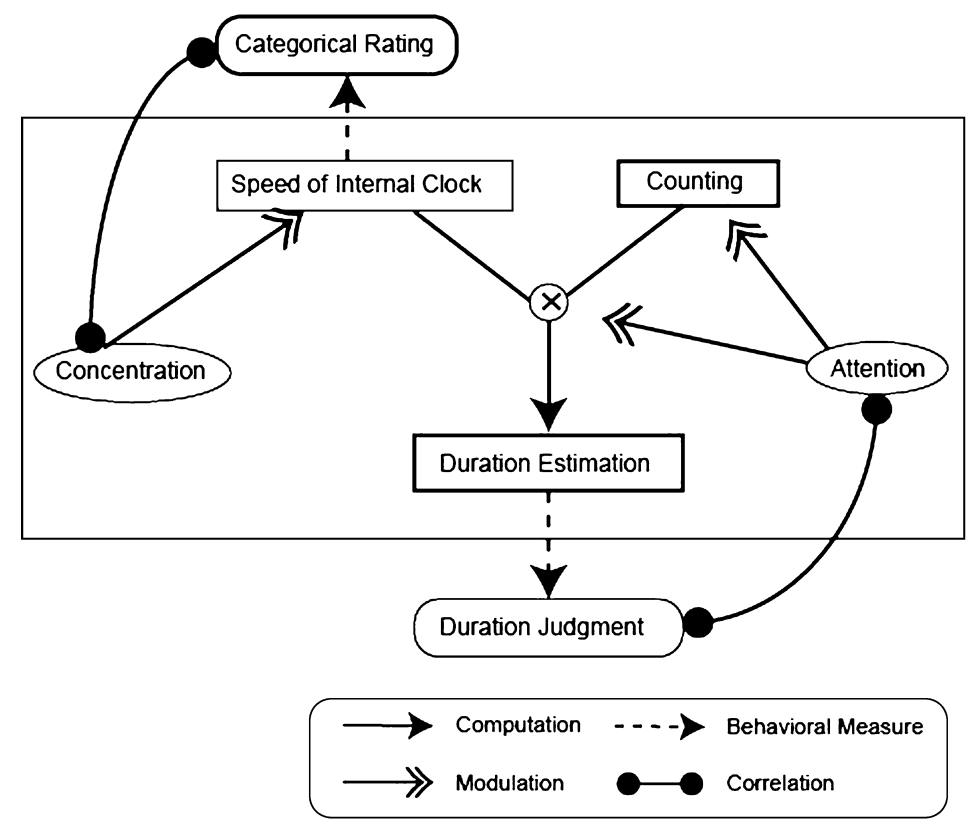

Fig. 2. Schematic illustration of the relationship among concentration, attention, and time perception.

\section{Methodological Considerations}

Since flow experiences are relatively rare in everyday life, the experimental induction of flow has been known to be difficult. Thus, the current study may include few, if any, flow experiences. However, it is also true that most of us have had some experiences in a highly concentrated state, such as sporting events, playing music, and games, which share some characteristics with flow experiences. In this respect, the experiments employed in this research probably induced a certain number of highly concentrated states.

One may argue that the significant negative correlation between concentration and time judgment with categorical scale reflects simply our metacognitive belief that time flies when we concentrate, or the effect of a third variable such as fatigue affecting both concentration and duration estimation. Although we cannot completely exclude these possibilities, the lack of correlation observed in some tasks argues against it. Indeed, the $6 \times 6$ puzzle, oral reading, and Reversi game tasks failed to show negative correlation in Experiment 2. If participants simply judge time based on a general belief, or a third variable mediates the correlation, these tasks should show a similar pattern.

Some tasks, in particular, $6 \times 6$ puzzle, oral reading, and Reversi showed different patterns of result in the current study, suggesting that the relationship between effort and concentration is more complicated than we assumed. For example, although we defined effort as a unidimensional notion, subjective feeling of effort and effort as resource deployed for task execution may be dissociable, which makes the relation between effort 
and concentration judgment more complex. Future studies are necessary to clarify psychological structure of effort and concentration.

\section{Concentration, Flow, and Happiness.}

Concentration and flow experiences have been treated as positive experiences in the sense that they are usually accompanied by happiness. Subjective and anecdotal reports repeatedly confirm that flow experiences alter time perception, such that time flies during the flow. We have provided a piece of experimental evidence supporting this feeling, and more importantly, we show that this is unlikely to be reduced to an effect of attention. Unlike the effect of attention, which biases temporal duration judgment, concentration or flow affects the subjective feeling of time, but not duration judgment. The effect of concentration may thus be more adaptive than the effect of attention, in that concentration only alters the feeling, and not the temporal estimation, which is often critical for survival.

\section{REFERENCES}

Block, R. A., \& Zakay, D. 1997. Prospective and retrospective duration judgments: A meta-analytic review. Psychonomic Bulletin \& Review, 4, 184-197.

Brainard, D. H. 1997. The psychophysics toolbox. Spatial Vision, 10, 443-446.

Chaston, A., \& Kingstone, A. 2008. Time estimation: The effect of cortically mediated attention. Brain and Cognition, 55, 286-289.

Csikszentmihalyi, M. 1990. Flow: The psychology of optimal experience. New York: HarperCollins.

Csikszentmihalyi, M., \& Larson, R. 1987. Validity and reliability of the experience sampling method. Journal of Nervous and Mental Disorder, 175, 526-536.

Csikszentmihalyi, M., \& Nakamura, J. 2010. Effortless attention in everyday life: A systematic phenomenology. In B. Bruya (Ed.) Effortless Attention: A New Perspective in the Cognitive Science of Attention and Action (pp. 179-189). MIT Press: Cambridge: MA.

Deci, E. L., \& Ryan, R. M. 1985. Intrinsic Motivation and Self-Determination in Human Behavior. New York: Plenum Press.

Ivry, R. B., \& Schlerf, J. E. 2008. Dedicated and intrinsic models of time perception. Trends in Cognitive Sciences, 12, 273-280.

Kahneman, D. 1973. Attention and Effort. Englewood Cliffs, NJ: Prentice-Hall.

Keller, J., \& Bless, H. 2008. Flow and regulatory compatibility: An experimental approach to the flow model of intrinsic motivation. Personality and Social Psychology Bulletin, 34, 196-209.

Lavie, N. 1995. Perceptual load as a necessary condition for selective attention. Journal of Experimental Psychology: Human Perception and Performance, 21, 451-468.

Lewis, P. A., \& Miall, R. C. 2009. The precision of temporal judgement: Milliseconds, many minutes, and beyond. Philosophical Transactions of the Royal Society: B, 364, 1897-1905.

Moller, A. C., Meier, B. P., \& Wall, R. D. 2010. Developing an experimental induction of flow: Effortless action in the lab. In B. Bruya (Ed.) Effortless Attention: A New Perspective in the Cognitive Science of Attention and Action (pp. 191-204). MIT Press: Cambridge: MA.

Pelli, D. G. 1997. The video toolbox software for visual psychophysics: Transforming numbers into movies. Spatial Vision, 10, 437-442.

Yamaguchi, S. 2004. Children's Brain is Located on their Skin. (In Japanese). Tokyo, Japan: Kobunsha.

Zakay, D., \& Block, R. A. 2004. Prospective and retrospective duration judgments: An executive-control perspective. Acta Neurobiologiae Experimentals, 64, 319-328. 